http://doi.org/10.15359/ree.15-1.11

[Cierre de edición 30 de junio del 2011]

\title{
Más allá del género
}

\section{Beyond gender}

\author{
Pablo Sisfontes Guilarte \\ División de Educación Básica \\ Centro de Investigación y Docencia en Educación (CIDE \\ Universidad Nacional \\ Heredia, Costa Rica \\ psisfont@una.ac.cr
}

Recibido 06 de setiembre de 2010 • Aceptado 09 de marzo de 2011

Resumen. El propósito del presente ensayo es describir, desde la cotidianidad, la influencia de la palabra en las canciones populares y destacar, al mismo tiempo, cómo lo cotidiano, lo que vemos, escuchamos y vivimos son poderosas herramientas de aprendizaje duradero en la construcción de las representacio-nes culturales relativas al género. Se destaca la influencia de las letras de las canciones populares en la construcción de la identidad masculina. Además, cómo esto determina las relaciones entre los sujetos, sean hombres y mujeres. Se plantea la necesidad de romper con modelos sexuales estereotipados que generan la violencia contra las mujeres y algunos hombres, en un contexto de una sociedad patriarcal, en procura de una sociedad más democrática y equitativa, sobre la base del principio de igualdad.

Palabras claves. Género, educación no formal, socialización, identidad.

Abstracts. The purpose of this essay is to describe, based on the everyday life, the influence of words in popular songs and highlight, at the same time, that what we see, hear and live everyday are pow-werful tools of long-lasting learning in the construction of gender-related cultural representations. The study emphasizes the influence of popular song lyrics in the construction of male identity, and how that determines the relations between men and women. It points out the need to break stereotypical gender models, which generate violence against women and some men in the context of a patriarchal society, to pursue a more democratic and equitable society based on the principle of equality.

Keywords. Gender, non-formal education, socialization, identity.

$$
\begin{array}{r}
\text { A Mónica y Paola, } \\
\text { ambas tienen por segundo nombre Sofía, } \\
\text { mis hijas, yo su padre; } \\
\text { por esta relación que nos define } \\
\text { como seres amorosos, de carne y hueso, } \\
\text { porque sin ellas no soy." }
\end{array}
$$

\footnotetext{
Educador, graduado de la Universidad Nacional (UNA), Costa Rica. Doctor en Educación, Universidad La Salle, Costa Rica. Profesor e investigador de la División de Educación Básica del Centro de Investigación y Docencia en Educación (CIDE) de la Universidad Nacional, Costa Rica. Actualmente es el director de la División de Educación Básica del Centro de Investigación y Docencia en Educación (CIDE) de la Universidad Nacional, Costa Rica.
} 
¿Por qué me gustan las baladas si mamá vivió en tiempo de rancheras y boleros?

Entre los más lejanos recuerdos de infancia, quizás los más tiernos, tengo el de mi madre "haciendo oficio" en tardes de invierno. Ella planchando y yo entonando una canción en un "ciclo piano", una especie de marimba con teclas que era toda una sensación entre mis escasos juguetes. ¿Qué soñaba mi madre en aquel entonces? Nunca lo sabré, pero yo soñaba con ser cantante como el charro que, según mi mamá, tenía un mechón blanco en su cabellera -después supe que se llamaba Miguel Aceves Mejía-. Mi madre planchaba y tal vez soñaba. Yo cantaba para alegrarle sus tardes de labores domésticas:

\section{"Canto desde tu ventana \\ pa' que sepas que te quiero \\ tú a mi no me quieres nada \\ pero yo por ti me muero. \\ Dicen que ando muy errado \\ que despierte de mi sueño \\ pero se han equivocado \\ porque yo he de ser tu dueño."}

Primera lección recibida sin darme cuenta: las mujeres y los hombres somos diferentes, pues ellas pueden ser mi posesión. Así es como se aprende a ver natural cualquier manifestación de poder sobre las mujeres. A la vez, con este ejemplo, es posible manifestar, de entrada, cómo la música puede y ejerce una tremenda influencia en el aprendizaje. En este caso, la sociedad enseña sus valores y los entroniza en las mentes tiernas de los niños para perpetuarse en sus modelos de dominación, a partir de la discriminación que surge de tratar de manera diferente a las personas dependiendo de su sexo, tal como afirma Lamas (1994). Es evidente que en las canciones que escuchamos en la niñez (los boleros y rancheras, para citar dos géneros) y cuando llegamos a adultos (las baladas y la música trova, para citar otros dos) resultan ser, en la categoría de género, poderosas herramientas que utiliza la sociedad para simbolizar la diferencia sexual y establecer normas y expectativas sociales sobre los papeles, las conductas y los atributos de las personas, en función de sus cuerpos (Lamas, 1994). Por tanto, es posible afirmar que la sociedad utiliza, por ejemplo, las canciones y música popular para interiorizar estos valores de género como experiencias de vida cotidiana. Lo cual tiene un poder especial, pues al existir una identificación afectiva con el ritmo y la letra, dichos valores dejan huella en nuestras mentes y luego se transfieren, naturalmente, a la aplicación de los mismos en nuestros estilos de vida y de nosotros mismos como sujetos sociales.

Mi mamá planchaba, yo era su compañía y la "Serenata huasteca" no nos dejaba escuchar la lluvia allá afuera. Sin embargo, en mis imágenes, puedo escucharla, porque tengo ese recuerdo muy arraigado.

A los tres o cuatro años de edad ya estaba aprendiendo que las mujeres pueden ser vistas como objetos. Las había buenas y malas; las buenas eran como mi mamá: Mujer callada, trabajadora en el hogar, cargada de sueños, con una tristeza que heredó a su hijo y una pasión por las canciones que se escuchaban en la radio, justo antes de "Escuela para todos."

Mis sueños, los de ella y sus canciones de buena cristiana daban magia a las mañanas soleadas impregnadas de olor a guayaba; cuando lavaba y cantaba una que quedó grabada en mi memoria: 


\section{"Alabaré alabaré \\ Alabaré alabaré \\ Alabaré a mi Señor."}

Claro, aunque el ritmo era pegajoso no entendía bien de qué trataba. (¡Qué interesante!) Hoy puedo recordar canciones de mi infancia y tomar conciencia del poder que guardan estas como herramientas de aprendizaje; con ellas de fondo en el marco de mi infancia y adolescencia, conviviendo con mi madre, hermana, dos hermanos y con la esporádica visita de mi señor padre, fui construyendo mi identidad masculina, propia de una sociedad liberal fundamentada en concepciones patriarcales de dominación. (Lo interesante es que recuerdo casi todo lo vivido en mi infancia con bastante claridad, pero tengo notables dificultades para recordar esa balada que recién escuché en mi radio. Tengo la melodía, y alguna imagen, pero no puedo acordarme. Bueno ya me acordaré...). Según Lozanov (2005), padre de la pedagogía desugestiva, con ayuda de la música es posible aprender mediante procesos de "seudo actividad" y relajación, de una forma acelerada y eficaz, prácticamente cualquier información, pues se potencian las capacidades paraconscientes. Este tema de la música y su influencia en la formación o construcción de mi identidad y cómo esto determina las relaciones entre los sujetos, sean hombres y mujeres, bien

Existen múltiples representaciones culturales de la constante biológica universal de la diferencia sexual. Las representaciones son redes de imágenes y nociones que construyen nuestra manera de ver, captar y entender el mundo. Las fuentes principales de nuestras representaciones son tres: los preconceptos culturales, las ideologías (no en el sentido marxista de falsa conciencia sino como discursos sociales) y la experiencia personal. Vamos percibiendo estas representaciones desde la infancia, mediante el lenguaje y la materialidad de la cultura (los objetos, las imágenes, etc.). La relativa al género antecede a la información sobre la diferencia sexual. Entre los dos y los tres años, niñas y niños saben referirse a sí mismos en femenino o masculino, aunque no tengan una elaboración cognoscitiva sobre la diferencia biológica; diferencian la ropa, los juguetes y los símbolos más evidentes de lo que es propio de los hombres y las mujeres y de lo que es propio de las mujeres (del género). (Lamas, 1994, pp. 7-8) merece estudiarse con mayor detalle.

Otro de los recuerdos tiernos, por ser primeros, es el de mi carrito de metal: una ambulancia; ¡cómo me gustaba jugar con ella en la acera de la plaza a la que me llevaba mi hermana! Al frente la fábrica de "alborotos", esas pelotas de palomitas de maíz envueltas en sirope que ya no se ven ni en la pulpería de don Elías. Cómo me reí aquella vez cuando a mi hermana, por ir a comprar recortes (los sobros de la confección de las extraordinarias bolas dulces) que eran muy baratos,

Desde la antropología cognitiva sabemos que nuestra conciencia ya está habitada por el discurso social: nacemos en una sociedad que tiene un discurso sobre el género y que nos hace ocupar cierto lugar. (Lamas, 1994, p. 7) como a 10 céntimos, la picaron las abejas. Lo triste fue el día que perdí el carrito, en esos momentos de juegos de los niños y niñas grandes y yo detrás de ellos hasta el cansancio. Lo dejé perdido en aquella acera donde solía jugar. ¡Qué tragedia aquella!, lloraba y lloraba sin esperanza de que algo me consolara. Solo mi hermana podía hacer algo. Ella siempre estaba cerca cuidándome, ahora me pregunto si era esa su tarea. La de empeñar su vida de juegos e infancia en cuidarme, una forma de liberar a mi madre de esta tarea para que ella pudiera hacer otras propias de la casa. Era la única mujer de tres hermanos más, pero sólo la recuerdo a ella en esta nebulosa subjetiva que conforma mi infantil paisaje. Lo cierto es que no sé si apareció mi carrito, pero aún lo extraño y a veces me sorprendo buscándolo cuando me paseo por los estantes de juegos en las librerías y bazares. Ahora puedo preguntarme, también, qué otras cosas no materiales estaré 
buscando en mi adultez que quedaron perdidas en la construcción de mis afectos. Mi madre, que no llegó a tercer grado de escuela, era muy cristiana, leía mucho. Su libro favorito La Biblia y se sabía pasajes de memoria. Siempre admiré en ella esta cualidad. "El señor es mi pastor nada me faltará" (Salmo 23, Biblia de Jerusalén) solía recitar. Claro, ante mis ojos de niño, en mi casa sobraba espacio, pues no había muchas cosas ni adornos en ella. Pero eso no importaba: siempre tenía a mi mamá y hermana cerca de mí. Cuando comienzo a tratar de recordar a mis hermanos, los ubico buscando una bola debajo de las tablas del piso. Una

"Como me piden que ame si mis sentimientos siempre han sido negados" linda bola verde que fue fuente de alegrías por un rato. Y no podía faltar "la Violi" en los recuerdos de infancia que conformaron la base, para bien o para mal, de mi actual personalidad adulta. " $L a$ Violi" era una linda perra de colores negro y blanco, tan inteligente que tocaba la puerta cuando se quedaba afuera. Un día no vino a la casa. Mi madre dijo que se fue a morir lejos para no hacernos sufrir. ¡Era tan inteligente...! No recuerdo si lloramos esta pérdida, pero ya la casa nunca más fue la misma.

El primer recuerdo de mi padre proviene de una foto de un paseo de domingo al Parque Bolívar. En ella estamos con él, mi hermana, mis dos hermanos y yo. (Por cierto no guardo registro de que alguna vez estuviera toda la familia completa en algún momento, durante toda mi vida de infancia y adolescencia). Ellos grandes y yo como un frijol. Un frijol blanco porque así aparezco vestido en esa antigua fotografía. Igual que cuando me llevaron al taller mecánico de mi papá; ese día, cuando él venía feliz a alzarme, alguien le increpó que no me alzara ni me besara porque con esas manos sucias de aceite y con esa ropa sucia de obrero echaría a perder mi ropita blanca. Aún extraño ese abrazo de oso y el beso de ese hombre gigantesco que era mi papá, cuando yo apenas tenía tres o cuatro años.

Con el tiempo comencé a verlo cada vez más pequeño. No me daba cuenta de que era yo quien estaba creciendo. Segunda lección aprendida, entre muchas otras de las que quizá no tengo conciencia: los hombres no besan ni abrazan. Eso es cosa de mujeres y mucho mejor si tienen las manos limpias. También, desde aquella época en que perdí el carrito comencé a escuchar, a menudo, que "los hombres no lloran ni con las tripas por fuera."

Eso era algo parecido a lo que decía mi mamá con frecuencia, cuando alguno de mis hermanos o yo mismo, peleaba con mi hermana, muchas veces, más allá de las palabras. "A las mujeres no se les toca ni con el pétalo de una rosa." $Y$ "los hombres con los hombres, las mujeres con las mujeres." Ustedes no se imaginan lo poderosas que esas palabras se fueron hacendando en mi cabeza. Tanto como las canciones que escuchaba y me aprendía sin siquiera darme cuenta.

Mis padres no hablaban mucho, pero decían frases como esas que se clavaban como dardos en mi mente, que aún hoy me sorprendo tratando de quitármelos; a veces, me atrapo diciéndoles lo mismo a mis estudiantes de escuela y colegio. Así fue como se fue construyendo en mi subjetividad la cultura de género y los conceptos de masculinidad y feminidad, como algo diferenciado y complementario. Incluso mis sentimientos homofóbicos y hasta xenofóbicos también los he reproducido como algo natural. Así ya se nos marcó la cancha a los siete años, nosotros jugábamos fútbol y otros juegos de verdaderos hombres, como "Policías y ladrones" o "Combate", donde la pelea iniciaba antes del juego, porque casi siempre todos queríamos ser de los buenos, sobra decir, los americanos, los policías o los vaqueros. Claro, de vez en cuando había una niña, la que nos gustaba a todos, jugando con nosotros, "la marimacha” le decían. Aún recuerdo el día en el cual al jugar de vaqueros e indios la dejamos amarrada a un palote en el patio de don Edgar (la casa donde trabajaba como servidora doméstica, -antes decíamos "de empleada"-, la mamá de Óscar). Mientras 
jugábamos llegó alguien con una bola y cambiamos en el acto las pistolas y los caballos por una extraordinaria mejenga en media calle y nos olvidamos no solo de quiénes fueron los ganadores, si los vaqueros buenos o lo indios malos (Esas mejengas famosas que duraban toda la tarde: " $A$ los 5 cambio y a los 10 termina”) sino también de Rosita. Bueno, como 2 horas después, es difícil recordar el tiempo de aquellos tiempos, nos acordamos de Rosita, la doncella que los indios habían dejado amarrada a un palote. Hoy nos reímos, pero aquello provocó hasta discusiones entre los mayores y pasó mucho tiempo antes de que la niña a quien le gustaban los juegos de hombres se integrara como una más a nuestro grupo, a nuestra pandilla de fútbol por las tardes y juegos por las noches. Algunos de estos los hacíamos con las niñas como el de "Turca-turca": "Turca turca la gran Turquía, la más hermosa será la mía." Diablos, otra vez esto de las posesiones. Lindas noches de socialización lúdica, donde comenzamos a enamorarnos y a sentir que las manos de las niñas eran más suavecitas y bonitas que las de los compañeros. Entre esos juegos nos dimos los primeros besos, como los artistas de las novelas, pero con la inocencia del que descubre hormigas debajo de las piedras. Ya en esa época todos en el barrio éramos alumnos de la niña Norma, ella era la novia de todos.

A propósito de las hormigas, mi mamá me contaba que cuando ella era niña pasaba horas de horas viéndolas llevar hojitas a los hormigueros, y ella jugaba, hacía experimentos con un palito, tratando de confundirlas en su eterno caminar con un manto verde a cuestas. "ah, si yo hubiera estudiado, donde estaría en este momento." "Sabes - me relataba-, en mi casa solo los hombres podían estudiar, al punto de que yo aprendí a leer y a escribir a escondidas, mi hermana Pacha me enseño" ¿Qué tiempos aquellos!, yo era su eterna compañía, claro ahora cantaba menos porque tenía que hacer tarea por las tardes antes de irme a jugar al barrio. "Su abuelo tuvo grandes fincas", me contaba, "y mucho dinero; de 14 hermanos, 6 mujeres y el resto hombres, ninguna mujer obtuvo ni papa. Su abuelo Francisco repartió todo entre los hombres que se dedicaron a botar la fortuna en guaro y mujeres. Las mujeres no tenían derecho a nada. Sólo José, su tío, aprovechó y se hizo de plata con lo que le tocó. Los demás quedamos pobres y las mujeres más. Hijo, ya a los 16 años era aprendiz de enfermera y yo fui una de las buenas, hasta que conocí a ese que es su tata. Ahí se acabó mi sueño de ser enfermera para convertirme en la "dueña de la casa”. Es que a ese viejo sí lo quería... hasta que comenzó a andar con otras mujeres y a botar todo el dinero en ellas y en otros vicios. Ese viejo también fue un tonto, porque tuvo muchas oportunidades y las desperdició por su mal carácter y por despilfarrarlo todo. Nunca guardó nada.”

Bueno, yo no entendía aún la diferencia; lo cierto es que como quería a mi padre tanto como a mi madre, hermana y hermanos, y deseaba que llegaran los domingos, cuando mi papá visitaba mi casa, para sentarme en su regazo a que me relatara historias; muchas veces, ese deseo se empañaba con las quejas de mi mal comportamiento y el maltrato que hacía a mi madre. Recuerdo que, a veces, ella le decía a mi padre que "yo le contestaba de mal modo y que no hacía caso" y cosas por el estilo; mi papá me miraba como el oso que yo creía que era, y luego de un regaño me daba un rato de atención contándome sus historias. Los domingos comíamos bien. Él traía mucha comida a casa, pero entre los recuerdos que tengo era que mi mamá le servía como si fuera un rey. Mi mamá me dijo una vez que con mis otros hermanos hubo ocasiones en que si se le caía un cubierto a alguno de ellos, le decía que no lo juntara porque para eso estaba su mamá. Eso me lo contaba mi mamá con un gran resentimiento, al tiempo que me decía, que eso ya nunca más volvería a pasar, que ese viejo no merecía nada, ni pizca de cariño de parte de ella, que lo único que le agradecía era los hijos que le había dado. He aquí un claro ejemplo, sobre la narrativa histórica sobre sexualidad de corte esencialista biologista con que nuestra sociedad liberal educó a los hombres y las mujeres, donde se pone en evidencia pautas de dominación, subordinación que moldea lo sexual y que 
nosotros tomamos de ese contexto sociocultural. Y todavía hay más en mi propia experiencia vital de construcción cultural sobre el género. Cuando yo ya tenía conciencia de los almuerzos de los domingos, lo único que recuerdo es que mi madre servía a todos y luego ella se sentaba a la mesa. ¡Cómo comíamos los domingos cuando llegaba mi papá a casa! Durante la semana nunca faltaron el arroz y los frijoles pero los domingos hasta carne comíamos.

Ya por esa época yo era todo un cantante. Me gustaban las de Julio Jaramillo:

"Tu carta que no llega

mi fe que se hace sombra

la luna que se oculta

por no verme llorar...

no sé por qué no me has escrito tu

si sabes que sufriendo estoy...

También el rock en español:

Anoche no dormí

lo que hice fue llorar

llegué al amanecer y el recuerdo de ti

no me deja dormir

siempre en mi mente estás...

Ya no cantaba tanto para mi mamá. Lo hacía para las chicas de mi barrio en el corredor de la casa de doña Daisy. Yo deseaba ser el chico del barrio para alguna de ellas, especialmente para una:

"Adiós chico de mi barrio

adónde de prisa vas aun

pasas en bicicleta, no te puedo alcanzar...

Desde luego, cuando me monté en una bici no era de mi propiedad; ahí solo los hijos de los ricos podían tener una; yo era pobre, pero eso no importaba mucho en mi barrio; que fuera comunista sí importaba, al punto de que a algunos amigos no se les permitía andar conmigo, no fuera que eso se transmitiera. Por ese tiempo, mi hermano se fue a estudiar con una beca a Rusia. El mayor se fue, mi hermana que ya había salido del colegio, trabajaba en una tienda para que yo estudiara. Luego fue secretaria en un hospital de la capital y nos la fuimos jugando poco a poco. Hasta un televisor Hitachi de 17 pulgadas compró para una Navidad en un tiempo en que para ver "La flecha rota" había que pagar 15 céntimos, con derecho a un bollo de pan, donde doña Dora. "Los Episodios" nunca nos lo perdíamos, aunque la poza estuviera riquísima o el torneo de bolinchas estuviera de lo más y mejor. Esa tele causó sensación, pero tampoco nos apartó del barrio ni de los amigos.

Con las canciones de Enrique Guzmán, César Costa y Alberto Vásquez en mi imaginario y cancionero a cuestas, me cortaba el pelo al estilo de "los cuatro de Liverpool" en la Barbería de German, allí por el mercado de Heredia, y él tenía un extraordinario radio Phillips de tubos y de onda corta, que hasta Radio Habana se escuchaba. Ahí aprendí de un señor que se llamaba Fidel Castro, que era malo como los diablos, pero que a mí me llamaba la atención tanto como "Chucho el roto", porque a como decían en la radio ayudaba a los pobres y yo era pobre, me sentía pobre, 
porque era algo que me habían inculcado con el "Dios proveerá." Se me olvidaba decirles que en la barbería iba a escuchar Radio City y Radio Eco, y escuchaba los boleros que ya había oído cantar a mi madre cuando me dormía.

"Mozo sírveme la copa rota

sírveme que me destroza esa fiebre de obsesión

mozo sírveme la copa rota

que quiero sangrar gota a gota

el recuerdo de su amor"

Con la ayuda de José Feliciano, comencé a comprender que aunque la mujer era un objeto de nosotros, los hombres, era muy difícil conseguir que la que a mí me gustaba se fijara en mí. Así que terminaba de novio (de mano nada más esto tenía que quedar claro), ¡ah, y era novia a escondidas!, nadie en el barrio tenía que darse cuenta, aunque luego todo el mundo sabía quién era la novia del momento, porque en mi barrio cambiamos de novia a menudo o las novias nos cambiaban a nosotros. Algo así como cada mes. Siempre me gustó más una que nunca se fijó en mí y, lo más interesante, es que a esas niñas las quería más. Sin darme cuenta me estaba preparando para más tarde convertirme en algo así como un cazador que iba a estar entrenado para obtener lo que quería de una mujer, para perder después el interés e ir en pos de otra posesión.

No se imaginan cuántos cuadernos gasté escribiendo poemas cursis para ellas. Pero no dio resultado, quizá esto habría tenido algún efecto si los mismos hubieran llegado a sus manos.

"Chiquita dulce y tierna
de rostro bello
como la luna
me llenas
adornando
chiquita la noche
iluminando chiquita
horas vacías
en el abismo del tiempo"

Tenía como 11 años y las canciones, algunas baladas, de Roberto Jordán cómo me gustaban:

"Hazme una señal chiquita, oh mi vida, que sepas que te quiero oh sí, pero si te gusto no me digas nada que tu silencio me lo diga todo"

En ese tiempo era todo un cantante profesional, me dejaba cobrar una peseta por canción con derecho a un chiste, aunque ciertamente me sobraba sentimiento, pero cantaba bastante mal. Así hice dinero que se quedaba en la pulpería del barrio, antes de convertirme en empresario de boxeo.

Recuerdo una vez que mi madre tuvo visitas y me envió a la estación del ferrocarril a comprar unos plátanos para preparar algo para la visitas. A mí me encantaban las visitas, porque 
me soltaba a hablar con ellas hasta cosas que no estoy seguro si se podían decir; entre una mezcla de orgullo y preocupación, me presentaban como un niño muy enamorado; yo hablaba hasta por los poros, mientras mamá me hacia unos ojos todos torcidos para que me callara. Después, como no le entendía sus gestos, me regañaba y al preguntarle por qué lo hacía, me decía una de esas frases que quedan pegadas a la conciencia de por vida: "El vivo por señas y el tonto ni a leñazos.” Siempre tuve dudas entre el genio y el tonto que se mezclaban en mi interior, pero al igual que John Lennon, me sentía genio o loco, pero no podía ser ambos al mismo tiempo, así que opté por hacerme pasar por loco. Rebelde dirían otros. Aunque nunca me castigaron físicamente, ¡cómo me castigaron el día de la mencionada visita!, porque nunca llegué a tiempo con los benditos plátanos; mejor dicho no llegué. Terminé el día hincado en un puñito de maíz. Se me olvidó debido a que en la calle los sucesos me absorbieron. Cuando llegué a la estación estaban boxeando los clientes de la cantina, en un pedacito de terreno, en un solar diría mi madre, a la par de la estación, y mis amigos viendo el espectáculo. Ese día fue el que me convertí en promotor de deportes, en este caso el boxeo; mientras la pelea estaba en lo mejor me fui donde "Mano" el zapatero, pues yo sabía que él tenía unos guantes de boxeo y, como yo le hacía mandados gratis a cambio del cuero para mis flechas, no tuvo reparo en prestármelos. Corrí, ofrecí los guantes a los boxeadores, que en su mayoría eran los borrachitos de las cantinas de la esquina, pues en esa esquina a 100 metros de mi casa y a 100 metros de la Escuela Braulio Morales, había ni más ni menos que 3 cantinas.

"Muy bien no boxeen a mano limpia señores, no se lastimen, aquí tienen los guantes a 25 céntimos el tiro, plata en mano, eso si" Las peleas eran a un round y con duración de dos o tres minutos y, mientras los mayores daban el espectáculo, alrededor del patio se reunía gente a mirar. Un amigo y yo recogíamos las contribuciones, eso era algo así como "pague por ver." A estas alturas del cuento se habrán dado cuenta de que las visitas ese día no comieron plátanos ni yo llegué rápido a casa. Aunque después, para que el castigo no fuera demasiado grande, tuve que compartir la ganancia. Ese día el espectáculo finalizó cuando llegó "La 190”, que era una famosa camioneta de la policía, donde nos llevaban a pasear al parque los policías cuando nos agarraban en alguna travesura; esa vez a los que se llevaron fue a los púgiles y tuve que llorar para que no me decomisaran los guantes de mi amigo el zapatero. Lo cierto es que después, en el barrio, circulaban los comentarios que me presentaban como un héroe con la cara sucia y, aunque quizá no era el más guapo del lugar, esta fama me facilitaba el conversar con las chicas del vecindario. Era todo un macho en pleno desarrollo. Con el dinero recaudado comprábamos revistas que leíamos a montones y los domingos cambiábamos afuera del cine Jara, antes de la tanda de 1:15 p.m. Las preferidas eran las del "Santo, el enmascarado de plata." En mi colección no podía faltar una que otra revista de "Susy" la que le gustaba a mi novia. Así, entre travesuras, aventuras y descubriéndome en mi rol de varón, se fue mi niñez y mucho más rápido mi adolescencia. Época en que fui muy estable con respecto a mi relación con las mujeres. Tuve una novia casi en todo mi peregrinar por el Liceo de Heredia. Luego, al ingresar a la Universidad Nacional, estuve más preocupado por estudiar y la práctica deportiva que en las mujeres. Aunque conocí a una compañera que luego se convertiría en mi esposa con la que tuve una hija. Una bella niña que tiene por nombre Paola Sofía. En este relato podría extenderme mucho más acerca de mi vida de colegial y universitario y luego como profesional en educación. No lo he hecho más por razones de espacio y para destacar lo que considero aquí lo más importante y que ha determinado en mucho el ejercicio de mi masculinidad en esta sociedad que me ha tocado vivir. Es el de corroborar, en carne propia, el hecho de que la construcción de género ocurre desde muy temprana edad y de manera casi imperceptible, y no 
por eso, muchas veces, sin violencia. Comparto con Chantal Mouffe el hecho de que resulta muy importante en estos momentos reconsiderar nuestras construcciones de masculinidad y feminidad en torno a personas de relaciones que somos. "No hay razón para que la diferencia sexual tenga que ser pertinente en todas las relaciones sociales (...)" (Mouffe, 2001, p. 86). Creo, al igual que ella, que es conveniente luchar por una sociedad que asuma, sobre la base del principio de igualdad, “(...) un proyecto de democracia radical y plural que no necesite de un modelo de ciudadanía sexualmente diferenciado en el que las tareas específicas de hombres y mujeres sean valoradas con equidad sino, una concepción verdaderamente diferente de qué es ser un ciudadano y de cómo actuar como miembro de una comunidad política democrática" (Mouffe, 2001, pp. 87), más allá del género. Mis hijas, mis compañeras a lo largo de mi vida de joven adulto, me ayudaron a ir cambiando los esquemas machistas con los que fui educado y a tratar de ser, entonces, una persona más sensible y tierna en mis relaciones con las personas, sean estas hombres o mujeres. También, a lo largo de mis estudios y luego, como profesional en educación, he aprendido mucho de mis compañeras y compañeros sobre lo relacionado con el respeto a la diferencia, la tolerancia, y la búsqueda permanente por una sociedad más igualitaria y equitativa.

La amalgama de profesiones, formación académica y experiencias vitales han sido un crisol que, conjuntamente con los desafíos planteados en la academia, las lecturas y los diversos puntos de vista, han marcado nuevas huellas y estructuras cognitivas, nuevas emociones se han despertado al encontrar también formas diversas de ver y apreciar la vida. Mi posición respecto a mi papel de educador en relación con el género, en este momento, se acerca al pensamiento de Chantal Mouffe. Precisamente, me resisto y lucharé en el futuro y en el aquí y ahora "(...) en contra de las múltiples formas en que la categoría "mujer" se construye como subordinación" (Mouffe, 2001, p. 93). Sin embargo, por otra parte, estimo muy conveniente el rescatar el fundamento feminista de la postura de Boff (2002); Capra (1998) y otros, respecto al ecofeminismo como una forma de nutrir teóricamente las discusiones sobre educación y género. El estudio de estos autores me ha permitido afinar posiciones ecológicas, políticas y, en general, desde una posición mucho más holística e integral, la problemática de género en la educación, especialmente desde las “(...) fuentes no formales de información (...)" como afirma el médico, sexólogo y educador, Fernández, tales como “(...) las imágenes ficticias de las revistas, la televisión, el cine y hasta las canciones, (...) que son las más arrasadoras." (Díaz, 2005, I25). Firmemente creo en esto porque, con base en mi experiencia vital, narrada en parte aquí, las canciones con que dejé mi cuna y que me acompañaron a lo largo de mi niñez jugaron un papel determinante en la construcción de mi identidad masculina, del rol de la masculinidad y la feminidad como constructos propiciadores de discriminación y dominación en mi persona y que, gracias a la sensibilización producto de nuevas experiencias de vida, algunas frustrantes y devastadoras, otras no tanto, me han permitido transformarla al tiempo que he ido educándome en la convivencia.

Finalmente, al cerrar este relato me he acordado de la canción aquella que no podía recordar hace un momento. Es precisamente de un poema de Benedetti musicalizado y cantado magistralmente por la desaparecida cantante mexicana Amparo Ochoa. A través de ella dedico esto a todas las personas que han hecho que valga la pena haber vivido en estos tiempos, especialmente a las mujeres. Son precisamente las relaciones que establecemos en nuestras vidas, con las demás personas, las que nos permiten ir construyendo nuestras propias subjetividades. Ustedes quedan con el poema y yo me quedo con la voz de Amparo Ochoa en mi memoria y con mi corazón latiendo más fuerte. 


\section{Vamos juntos}

Con tu puedo y con mi quiero vamos juntos, compañero.

Compañero, te desvela la misma suerte que a mí prometiste y prometí encender esta candela.

Con tu puedo y con mi quiero vamos juntos, compañero la muerte mata y escucha la vida viene después la unidad que sirve es la que nos une en la lucha.

Con tu puedo y con mi quiero vamos juntos, compañero.

La historia tañe sonora su lección como campana para gozar el mañana hay que vivir el ahora.

Con tu puedo y con mi quiero vamos juntos, compañero.

Ya no somos inocentes ni en la mala ni en la buena cada cual en su faena porque en esto no hay suplentes.

Con tu puedo y con mi quiero vamos juntos, compañero.

Algunos cantan victoria porque el pueblo paga vidas pero esas muertes queridas van escribiendo la historia.

Con tu puedo y con mi quiero vamos juntos, compañero. 


\section{Referencias bibliográficas}

Benedetti, M. (1986). Inventario. México: Editorial Nueva Imagen, S.A.

Boff, L. (2002). Ecología: grito de la Tierra, grito de los pobres. Madrid: Editorial Trotta.

Capra, F. (1998). El punto crucial. Buenos Aires: Editorial Troquel.

Díaz, R. (25 de septiembre al 2 de octubre de 2005). Sexo en el punto. La Nación.com Recuperado de http://wvw.nacion.com/teleguia/2005/septiembre/25/reportaje.html

Lamas, M. (1994, septiembre). Cuerpo: diferencia sexual y género. Debate Feminista, 10, Año 5, 3-31.

Lozanov, G. (2005). Sugestopaedia-Desuggestive Teaching. Comunicative Method on the level of the children reserves of the human mind [Enseñanza sugestopédica-desugestiva. Método comunicativo en el nivel de las reservas de los niños de la mente humana]. Viena, Austria: International Centre for Desuggestology.

Mouffe, C. (2001). Feminismo, ciudadanía y política democrática radical (Cap. 5). En El retorno de lo político. Comunidad, ciudadanía, pluralismo, democracia radical (pp. 77-93). Recuperado de http://es.scribd.com/doc/35319784/Mouffe-Chantal-El-retorno-de-lo-politico 